Dr. Perutz: The figure is an average one based on experiments carried out at the National Physical Laboratory. The determination of tensile strength is complicated because of the brittleness of ice and reproducible results are almost impossible to obtain. There is also the difficulty of producing really pure ice free from air bubbles.

Lt.-Cdr. J. CortlandT-Simpson: In the case of cirque formation with dust and detritus falling on the glacier, would this increase its strength and ability to eat into the mountain side?

Dr. Perutz: I think so. If sufficient quantities of detritus fell on the ice they might increase its strength and its erosive power.

Mr. W. H. WARD : You would have to have a very much larger amount of sand than wood pulp to make any difference to the strength of ice.

Dr. B. B. Roberts : It has been the practice in Scandinavia to use snow in battlements as a protection against cannon balls.

Dr. Perutz: I believe the Germans used this technique in Russia, too.

Mr. C. B. Croft Handley: The Russians supplied us with details of "ice concrete" used in field fortifications during the war. The projectile penetration figures compare favourably with ordinary cement concrete.

Dr. Perutz: As a protection against explosives pykrete is weight for weight as good as concrete.

The Chairman then closed the discussion with thanks to Dr. Perutz for his paper and the important data he had brought to light.

\title{
SNOW SURVEYING IN INDIA
}

THE official India News of 4 September 1947 publishes a preliminary account of the expeditions organized by the Central Waterways, Irrigation and Navigation Commission with the help of Dr. J. E. Church, the originator of the system of snow surveying. The expeditions were three in number, one each into East and North Sikkim and the third along the East Nepal border. In addition to Church, irrigation and hydro-electrical engineers accompanied by scientific and professional experts of the C.W.I.N.C. took part. The account continues :

The first expedition which started in April went eastwards from Gangtok, the capital of Sikkim, up to the pass Natha La (1 $3,000 \mathrm{ft})$. The second went northwards later in April from Gangtok up to Chunthang, the northernmost P.O. in Sikkim, and thence to Thanggu and Jha Ghu, climbing up to about $\mathrm{r} 6,500 \mathrm{ft}$. where snow was found. The third went along the East Nepal border, i.e. mainly over the ridges of the Singalila range, up to Nayathang, $12,600 \mathrm{ft}$., much of it over pathless and stony slopes.

The organization of a snow survey on the scale necessary to deal with run-off, from even a part of the enormous hinterland of mountains and glaciers which lie above the sub-continent, will be a task of very large proportions indeed. That Church, who is not a young man, has been willing to undertake its inauguration and take part in severe expeditions to great heights is a tribute to his unbounded energy and enthusiasm. Details will no doubt be communicated later. 